\title{
ANALYSIS OF SELECTED PROPERTIES 100CrMnSi6-4 SURFACE LAYER AFTER LASER MICRO-SMELTING
}

\begin{abstract}
The use of laser ablation phenomenon with the "thermal effect" to produce surface textures, mainly lubricant micro-containers in the form of spherical micro-bowls in the surface layer of $100 \mathrm{CrMnSi}-4$ alloy of bearing steel. This is interesting research topic. The application the local (zonal) laser hardening of the steel surface layer on the surface of the bearing raceway or casts gives technological opportunities to deploy those technologies in the production process. The article presents the selected results of the own laboratory studies of hardness, microstructure and surface stereometry bearing steel $100 \mathrm{CrMnSi} 6-4$ in different states after volume hardening and low tempering, as well as those obtained as a result of laser surface texturing and laser pulsed hardening. The study results can be used to modify the surface layer of $100 \mathrm{CrMnSi}-4$ bearing steel and in the nearest future use ablative laser texturing of the rolling bearings treadmill surface in the production of lubricanting micro-containers, for improving the wear resistance tribological pair of roller - raceway in the friction conditions.
\end{abstract}

Keywords: $100 \mathrm{CrMnSi6}-4$ bearing steel, technological surface layer, ablative laser texturing, laser hardening, microstructure

\section{Introduction}

Laser processing (except for cutting, bonding and perforation), as all types of surface treatments, is intended to change the geometric, physical and chemical properties of surface layers: from existing to desired. Those properties are mainly the formation (individual or combined) [1] of:

- $\quad$ surface topography (stereometry) by increasing or decreasing the surface roughness, surface sculpting,

- physical properties by increasing hardness, strengthening, but also imparting other specific properties, leading to the growth of usable tribological and fatigue properties,

- chemical properties, mainly corrosion resistance but also catalytic properties, absorption, and others.

Laser micromachining, just like laser processing, allows for the modification and combining of technical surface and its bending, disconnection and polishing. Some technologies of laser treatment can be carried out also at the macro level, but not all of them and not always [1]. Surface laser processing is used in the technological cycle of production. Since it renders it possible to process selected, small areas of the material, it also allows for the minimisation of mechanical deformations as a result of heat interaction, bringing them only to the area of heat interaction and residual stresses of their own. The range of laser heating applications is wide, because the heating of load usually takes place in the air, which makes it easier to operate the radiation beam and thus reach the inaccessible feed elements [2].
There are many methods of modifying the surface layer of metal construction materials through the application of high technology fascicular, such as electron, plasma, electrical discharge machining and laser. The latter, thanks to the full automation, possibility to control the process and its repeatability, allows for a quick and precise shaping (also local) of the surface layer of machine parts. The technology is used more and more often in surface engineering, tribology and the production engineering of machine parts made of different construction materials [1-8]. There are the following types of laser texturing [4]: free from cavities, over-the-measuring, cavities. Free from cavities laser texturing takes place, as the name suggests, without removing the material from the area of laser beam interaction and is connected only with the structural changes of the work piece, occurring in the phase transformation in the solid state or as a result of melting and solidification. This type of texturing occurs during laser melting hardening and hardening without melting [4]. Excessive laser texturing occurs with supplying the melting material in the area of laser beam incidence and it includes laser seal-in and sealon alloy. Loss-texturing proceeds with the removal of material in the area of laser beam incidence as a result of the ablation of the workable material: marking, engraving, the formation of "lubricating pockets" (areas with lubricant trays), increasing surface roughness, laser shock strengthening. Laser hardening without remelting causes phase transitions in a very short time by heating the material being modified to the appropriate phase transition temperature and fast or ultra-fast automatic cooling, 
resulting most often in hardening, in order to harden the selected portions of the surface layers of the construction material.

An example of this technology can be hardening without remelting of alloy structural steel for quenching and $41 \mathrm{Cr} 4$ tempering with a $\mathrm{CO}_{2}$ laser of continuous operation (cw) and average power density of $\mathrm{q}=0.6 \cdot 10^{4} \mathrm{~W} / \mathrm{cm}^{2}$. The author of this publication carried out a series of research work in this field [5]. For this technology, the heating rate is generally around $10^{6} \mathrm{~K} / \mathrm{s}$, and the cooling rate of approx. $10^{4} \mathrm{~K} / \mathrm{s}$. During laser hardening of iron alloys with carbon, the hardness and thickness of the hardened layer increases in general together with the increase of the carbon content, by applying the same machining parameters. This is due to inter alia an increase in harden ability and the reduction of austenitising temperature [4].

By carrying out technological processes at high and very high power densities of laser radiation $\left(10^{7} \div 10^{11} \mathrm{~W} / \mathrm{cm}^{2}\right)$, and with short exposure times of laser radiation on the surface of the modified material, it is possible to perform laser texturing of evaporate. Micro-craters (micro-reservoirs) were made on samples of single pulses. Each micro-crater was made with a different power density of laser radiation, in the range from $0.32 \div 1.06 \mathrm{MW} / \mathrm{cm}^{2}$.

As a result of laboratory experiments, with the use of different power density of laser radiation $(\lambda=1064 \mathrm{~nm})$ in the variants with an absorbent material (black ink) and without any absorbent, different shapes and geometric dimensions of the micro-craters were obtained. The increase in power density from 0.32 to $0.53 \mathrm{MW} / \mathrm{cm}^{2}$ causes almost the linear increase in the depth of the micro-craters from 3.36 to 5.29 microns. Increasing power density further above $0.53 \mathrm{MW} / \mathrm{cm}^{2}$ causes the slight increase in the depth of the micro-craters to the value of 5.45 microns. Probably the reason for such a significant decrease in the efficiency of laser texturing is the "laser plasma shielding effect", which greatly or even completely restricts (reflects, scatters) laser radiation [8].

With the increase of power density of laser radiation, also the diameter of the micro-craters, produced in the range of around $42 \div 76$ microns, increases. This significant increase in the diameter of the obtained micro-craters is probably the effect of increasing the dimensions of the generated cloud of laser plasma with the increase in the intensity of laser radiation. The created laser plasma directly interacts with the surface of $41 \mathrm{Cr} 4$ steel. With the increase of power density of laser radiation, also the plasma temperature rises and even greater pressure amplitude is generated [8].

\section{Ablative laser micromachining}

Depending on the distribution of the power density of laser beam, for example for the Gaussian distribution, different values of temperatures appear on the material surface to be heated with the concentrated laser beam with appropriate density radiation power. In the central radiation zone, depending on focusing the beam of radiation power density on the surface of the mate- rial being modified, the highest temperature reaching several hundred of degrees occurs, with the power density of around $\mathrm{q}=0.4 \times 10^{4} \mathrm{~W} / \mathrm{cm}^{2}$ and with the pulse duration of approx. $1 \mathrm{~ms}$.

On the other hand, using a larger power density of laser radiation, above $\mathrm{q}=08 \times 10^{4} \mathrm{~W} / \mathrm{cm}^{2}$ and above $10^{5} \div 10^{7} \mathrm{~W} / \mathrm{cm}^{2}$, and even $10^{13} \mathrm{~W} / \mathrm{cm}^{2}$, as a result of ultrafast heating up, melting, as well as evaporating the material, the temperature may reach the values of several and even tens of thousands degrees Celsius. The process of ultrafast heating up is accompanied also by the ultrafast self-cooling process, causing the crystallisation of the material from the liquid phase and the phase changes in the solid state, including self-hardening. The phenomenon of ablation may occur with the so-called "thermal effect", with the partial evaporation of the material, extrusion of the liquid material, crystallisation from the liquid phase and the processes of self-hardening and tempering the textured materials in the areas directly adjacent to the formed micro-crater (the lubricant reservoir). By ultrafast warming, for example of 100CrMnSi6-4 alloy steel bearing, to the correct austenitising temperature, and then to the liquid phase with a long period of heating up (microseconds and milliseconds), after the discontinuation of laser radiation, a quick auto-cooling occurs, causing the crystallisation of the material from the liquid to solid phase. At the time, the phase transitions occur as well. For a group of easily hardened steel, the martensitic transformation takes place most frequently in the cooling process, both in the remelted and crystallised zone and in the directly adjacent zone.

The aim of the laser micromachining process is to achieve the effect of the so-called laser "cold ablation" (the violent rupture of atomic linkages and the transition of the matter in the vapor state). This can be achieved at very high power densities and explosion time of pico- and femtosecond. Then a very shallow evaporate zone of the material is achieved. If a longer exposure time (nano- and microsecond) is used, an appreciable thermal effect accompanying laser ablation occurs. Then, the side effects in the form of the intense heating, melting and extrusion of the liquid material are produced. The clear heat affected zone is created, in which the phase and structural transitions occur. The laser interaction zones can have different shapes, e.g. dotted texture - spherical half-balls, or in the form of micro-channels constituting such lubricating cartridges for the machine elements working in different tribological systems. At very high power density laser radiation, i.e. greater than $10^{11} \mathrm{~W} / \mathrm{cm}^{2}$, the exposure time of radiation in the range of $10^{-12} \div 10^{-15} \mathrm{~s}$ (pico- and femtosecond lasers), the effect of the so-called "cold ablation" occurs, which is equivalent to sublimation. The complete evaporation of the heated and molten material in the zone and concentrated beam influence of very high power density occurs in a very short time. If power density is much higher, $10^{12} \mathrm{~W} / \mathrm{cm}^{2}$ and even $10^{15} \mathrm{~W} / \mathrm{cm}^{2}$, during the exposure of concentrated laser radiation from single nanoseconds / picoseconds up to femtoseconds, the ablation processes proceed very rapidly. Apart from rapid heating up and melting, a high pressure in the laser plasma zone is generated and it comes to the extrusion of the material, as well as to the partial or total evaporation of the material (sublimation). 
The described phase transformations occur in the micro-area created in the zone of the formed container as well as in the nano- and microenvironment. This process is ideal for surface laser texturing and it can be used as the final finishing machining on the surface of a rolling bearing raceway.

\section{Study}

The object of the laboratory tests was constituted by the surface layer of $100 \mathrm{CrMnSi6}-4$ bearing steel after volume hardening and low tempering, and also after volume hardening as above and laser modification - texturing and hardening. This steel is used in the production of rolling bearings. The study was performed on material slices taken from the roller outer ring of roller bearing.

The main aim of the laboratory tests in the field of texturing and laser hardening of the surface layer (SL) of 100CrMnSi6-4 bearing steel, was to:

- $\quad$ produce in the surface layer zone the micro-areas with the specified geometry of spherical micro-bowls as a microcontainer of lubricating factor,

- obtain high hardness in the zone adjacent to the lubricating micro-container in order to increase the exploitative hardness of the tribological system of raceway of the bearing - roller,

- $\quad$ obtain in the hardened area the finecrystalline martensitic microstructure in the zone near the surface, with high resistance to pitting and also wear under friction,

- $\quad$ evaluate the usefulness of laser texturing and surface hardening of the surface layer of bearing steel in the production processes of roller bearings.

In laboratory test on laser texturing, a stand with the $\mathrm{Nd}$ : YAG laser with the radiation wavelength of $\lambda=1070 \mathrm{~nm}$, working in the pulsed-mode with Galvo scanning head, was applied. The maximum laser power $-30 \mathrm{~W}$, the diameter of laser beam in the range of 15-100 microns, repetition frequency up to $100 \mathrm{kHz}$, the exposure time of single laser pulse of $10-100$ ns. The surfaces of samples after excision from the outer ring of the bearing were mounted, grinded, polished, and then, in order to increase the absorptivity of laser radiation, they were coated with absorbent in the form of black ink. In the process of hardening the surface zone of the bearing steel surface layer, the industrial stand of Rofin, the Integral pulse model with the Nd: YAG laser with the laser radiation wavelength of $\lambda=1064 \mathrm{~nm}$ was used. The position of the laser had the following parameters: maximum power $-12 \mathrm{~kW}$, the diameter of laser beam in the range of $0.05-4 \mathrm{~mm}$, repetition frequency of $0.5-20 \mathrm{~Hz}$, laser radiation exposure time of $0.5-50 \mathrm{~ms}$. The stand was equipped with a monitoring system, controlled manually or automatically (CNC), with the possibility to use shielding gas. Argon, as shielding gas, was used in the study. As part of the paper, the selected results of the laboratory tests of hardness, microstructure and surface layer stereometry of bearing steel in its various states, i.e. starting after the volume hardening and low tempering (microhardness of around 610 $\div 660 \mathrm{HV} 0.05$ ), are presented, as well as those obtained as a result of surface modification of the surface steel layer in the field of surface laser texturing and pulse laser beam hardening. In order to obtain the adequate average power density of pulsed laser radiation, necessary to implement the process of surface pulse laser hardening of top layer of the modified steel, the correct parameters of laser processing were selected (distance of the outbreak of the lens of the preheated surface heating time, repetition frequency, degree of covering the laser spot). As part of the conducted experiments, the pulse heating of the surface at different average power densities of laser beam was carried out. The experiments were conducted in the ambient air environment. The ablative texturing of the steel surface layer was carried out with the "thermal effect" with different power densities, from $1.2 \times 10^{5} \mathrm{~W} / \mathrm{cm}^{2}$ to $1.5 \times 10^{6} \mathrm{~W} / \mathrm{cm}^{2}$ during the laser pulse of around $10 \mathrm{~ns}$.

Laser hardening was conducted with power densities from $\mathrm{q}=1.1 \times 10^{4} \mathrm{~W} / \mathrm{cm}^{2}$ to $3.8 \times 10^{5} \mathrm{~W} / \mathrm{cm}^{2}$, with pulse duration of approx. 1 to $3 \mathrm{~ms}$. As part of the laboratory study, the following activities were conducted: the stereometry study of the layer of the modified steel, the measurements of microhardness as well as microstructure with the use of digital optical microscopy and scanning electron microscopy (SEM).In the first phase of the laboratory tests, a variant of laser micromachining with textured surface in the form of the spherical micro-bowls (Fig. 1.) with the filling level of $5 \%, 10 \%, 25 \%$ and $50 \%$, was used.

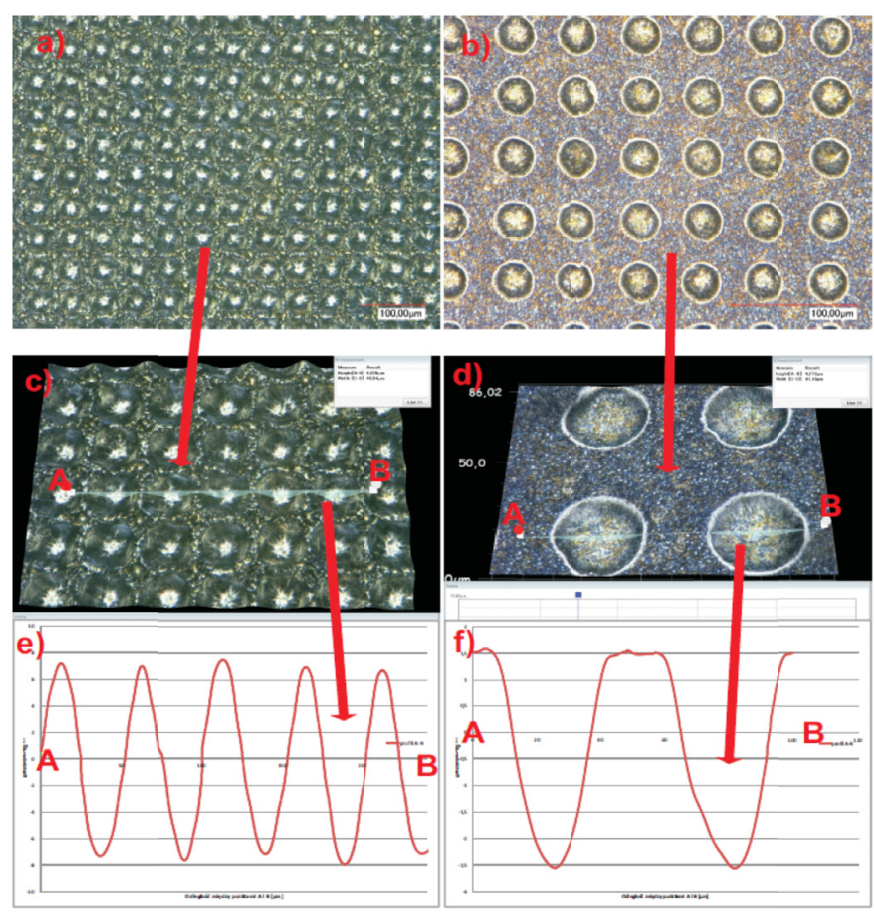

Fig. 1. View of the surface after ablative laser texturing $(a, c)$ and after ablation texturing and polishing the surface $(b, d)$, surface profile $(e, f)$

As a result of the conducted experiments, the regular geometric texture of the micro-containers in the shape of microbowls with the diameter of 30 to 70 microns and the depth of 0.2 to 15 microns, was obtained. 
In the zone adjacent to the micro-reservoir of all variants, micro-outflow with the height of $0.5 \div 10 \mu \mathrm{m}$ occurred. This effect is characteristic for ablating and is called the "thermal effect". The process of ablative laser texturing has many technological advantages, generates phase transformations in a very short time.

By using the pulsed fiber Yb: YAG laser, the ablative texturing of steel top layer was conducted with the "thermal effect" with different power densities. The results obtained are shown in Fig. 1.

Using laser beam source as pulsed laser with a very short pulse duration, pico or femto-second and a power densities in the range of $10^{9} \div 10^{13} \mathrm{~W} / \mathrm{cm}^{2}$, laser texturing realize without flash. In those conditions, the "cold ablation" effect, equivalent to sublimation, can be successfully achieved.

As a result of metallographic study carried out in the surface layer of the formed micro-container and in the micro-zone adjacent thereto, the highly dispersive martensitic microstructure in the near-surface zone was found. In the transition zone, martensitic-bainitic and bainitic microstructure was found.

Those microstructures were the result of the ultrafast phase transformations, occurring during the crystallisation of bearing steel alloy from the liquid phase formed during laser texturing. The characteristic microstructures in the container and around it are shown in Fig. 2.
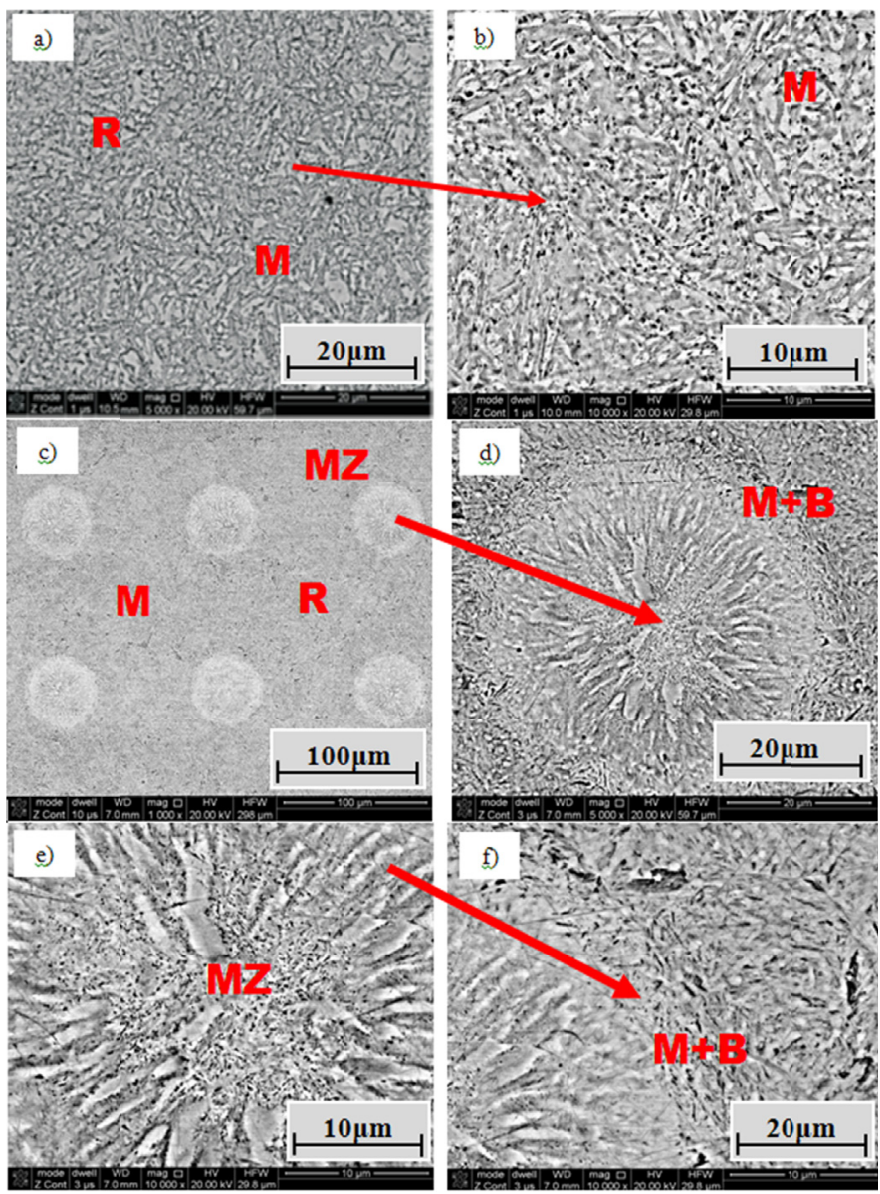

Fig. 2. The characteristic microstructure of $100 \mathrm{CrMnSi}-4$ steel after volume hardening $(\mathrm{a}, \mathrm{b})$, after volume hardening and ablative laser texturing (c-f); $\mathrm{R}$ - the core of material, MR - micro-reservoir, $\mathrm{M}$ martensite, $\mathrm{M}+\mathrm{B}-$ martensite + bainite
The microstructure of the core material $(\mathrm{R})$ after volume hardening had hardness in the range of $610 \div 660 \mathrm{HV} 0.05$, but after ablative laser texturing it increased to $800 \mathrm{HV} 0.05-$ 1000 HV0.05 (increase by around $60 \div 75 \%$ ), and locally even to $1100 \mathrm{HV} 0.05$.

The conducted insightful microscopic observations did not show defects in the microstructures, or the occurrence of microcracks on the surface top layer, as well as in the cross section of the micro-container. In the second stage of the laboratory tests, the process of pulse laser hardening of 100CrMnSi6-4 steel was carried out in the laboratory conditions with the use of the pulsed Nd: YAG Rofin laser, Integral type, equipped with automatic control CNC (table $x-y-z)$. The laser radiation wavelength of $\lambda=1064 \mathrm{~nm}$ was used in the tests. The experiments were also carried out in the atmospheric air environment.

The results showed that with the power densities of around $1.1 \times 10^{4} \mathrm{~W} / \mathrm{cm}^{2}$ only the local (zonal) heating of the surface layer of bearing steel is obtained, causing only tempering of material from around $650 \mathrm{HV} 0.05$ (the starting material after volume hardening and low tempering) to around $500 \mathrm{HV} 0.05$. With greater power densities of laser radiation of $\mathrm{q}=3.8 \times 10^{4} \mathrm{~W} /$ $\mathrm{cm}^{2}$, but no greater than $5.3 \times 10^{5} \mathrm{~W} / \mathrm{cm}^{2}$ (the "shielding laser plasma" effect), the surface effects of laser micro-melting, ultrafast crystallisation from the state of liquid with the simultaneous ultra-fast phase transitions in the range of micro-hardening and micro-tempering of the modified surface layer bearing steel were obtained in the central zone of influence of the laser. In the heated, melted and hardened area, the microcrystalline martensitic microstructure was obtained in the area near the surface and in the middle of the hardened zone, as well as the martensiticbainitic and bainitic in the transition zone. The microstructures were characterised by high microhardness in the range from 800 to $980 \mathrm{HV} 0.05$ in the hardening variant without surface remelting (Fig. 3a-c). In the case of hardening with remelting, the surface hardness even in the range of approx. $1100 \mathrm{HV} 0.05$ was achieved, mainly in the central zone of laser pulse (Fig. 3a,d,e), (Fig. 4a, b), (Fig. 5).

The unfavourable tempered zone was also found in this variant. During laser hardening with the effect of local microremelting, the hardened layers with the thickness of $10 \div 35$ microns were produced.

Those layers, however, had a developed surface which should be subject to finishing surface treatment (such as sanding and polishing).

The results of the preliminary tests show that a zone of higher hardness, as compared to the core of the material (about $1100 \mathrm{HV} 0.05$ ), was obtained in the surface layer (Fig. 6).

The technologies of texturing and laser hardening should be used as half finishing before finishing grinding. An important advantage of those technologies is a very small heat affected zone, which probably minimally impacts the state of deformation of the surface layer and, at the same time, also the residual stress.

According to the measurement results, it is possible, by hardening without remelting of $100 \mathrm{CrMnSi6}-4$ steel surface layers, to increase its hardness up to about $800 \div 1000 \mathrm{HV} 0.05$. By 

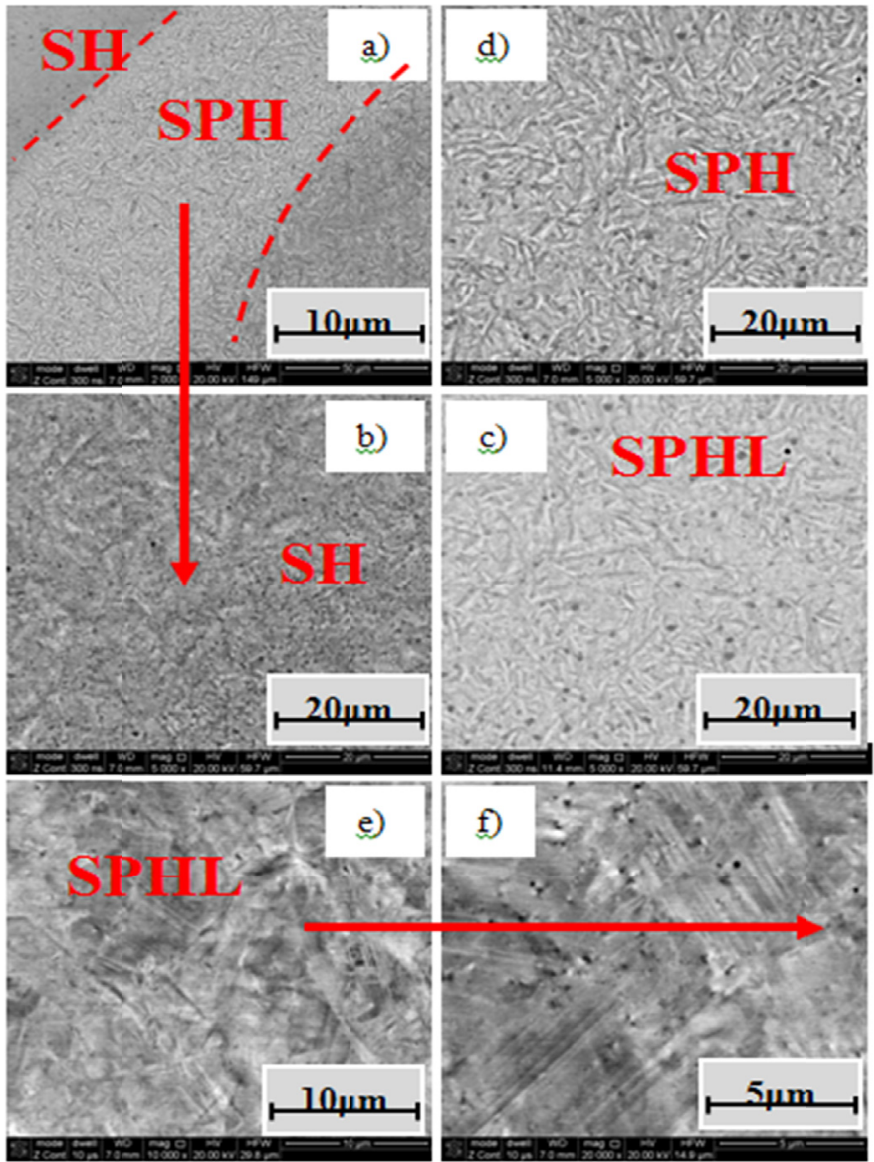

Fig. 3. The characteristic microstructure of $100 \mathrm{CrMnSi}-4$ steel after laser hardening at power densities of $\mathrm{q}=1.2 \times 10^{4} \mathrm{~W} / \mathrm{cm}^{2}-$ view from the top, SHL - laser hardened zone, SPHL - laser melted and hardened zone
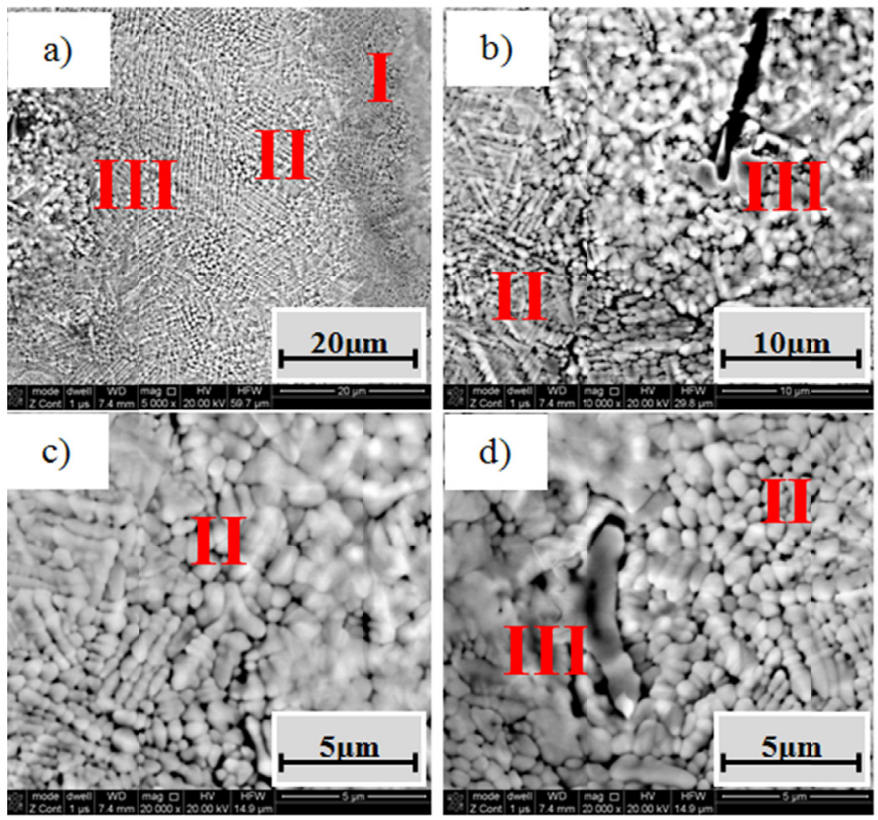

Fig. 4. The characteristic microstructure of $100 \mathrm{CrMnSi}-4$ steel after laser hardening at power densities of $\mathrm{q}=1.2 \times 10^{4} \mathrm{~W} / \mathrm{cm}^{2}-$ cross section

carring out laser hardening with the effect of micro-remelting, it is possible to obtain even the increase of microhardness up to $1100 \mathrm{HV} 0.05$.
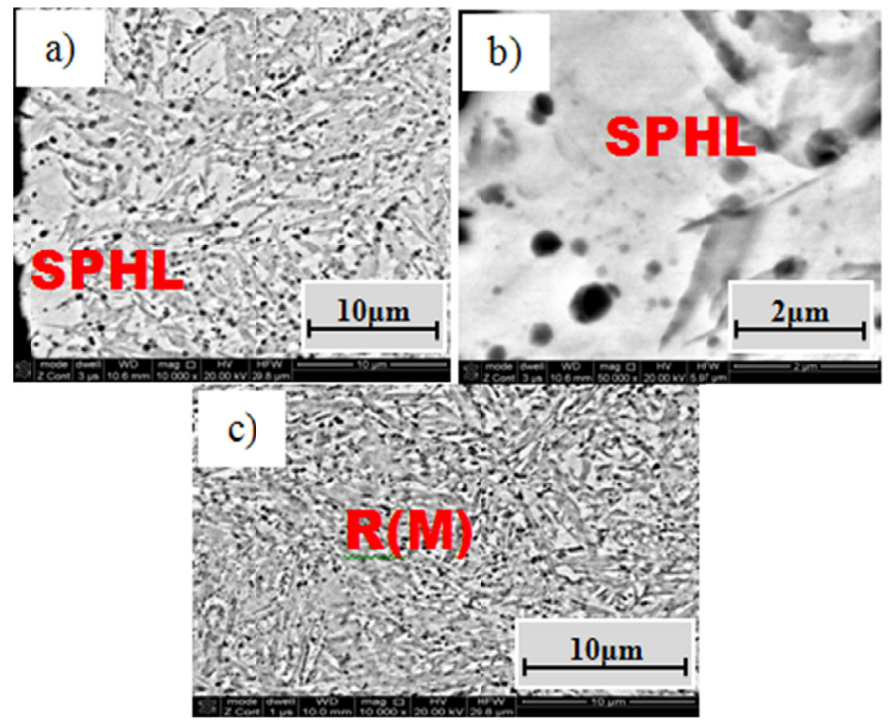

Fig. 5. The characteristic microstructure of 100CrMnSi6-4 steel surface after laser hardening with remelting at power densities of $\mathrm{q}=3.8 \times 104 \mathrm{~W} / \mathrm{cm}^{2-}$ visible arrangement of dendrites formed in the crystallization process of the liquid phase - top view: I, II, III - characteristic of laser melted zone and hardened with diverse systems dendritic (SEM)

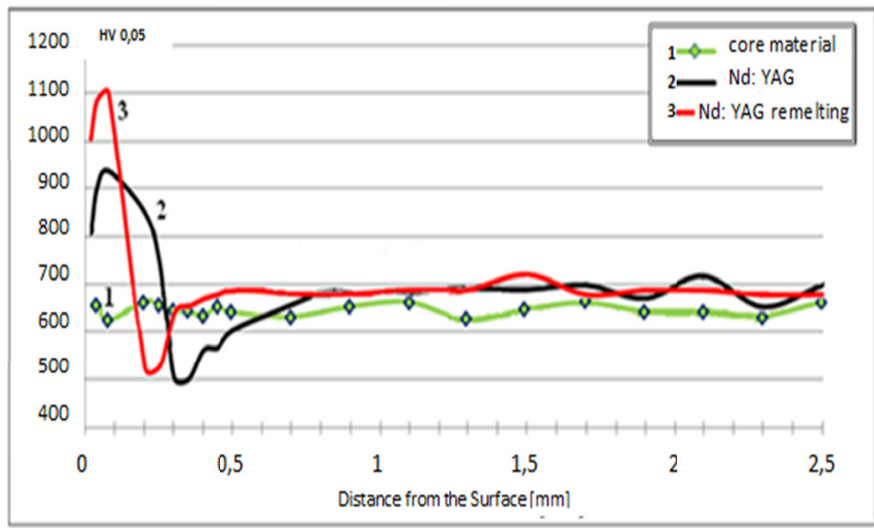

Fig. 6. Distribution of micro hardness from the surface into the core material (1) after hardening laser without remelting (2) and after hardening laser with remelting (3) Nd: YAG laser pulse, $\lambda=1064 \mathrm{~nm}, \tau$ about $3 \mathrm{~ms}$

\section{Summary}

In the process of parameter selection of texturing and laser hardening, the type of the laser radiation and the type of laser should be properly chosen, and also the correct distribution of power densities (as Gaussian, top of head, rectangular, and others) should be applied, because it significantly affects the shape of the textured zone and the homogeneity of the interaction of radiation.

A very important factor in the technological processes of laser texturing is the exposure time of laser pulse to the material, also. In the case of the very short exposure time of the laser beam (pico - and femtosecond) the so-called "cold ablation" occurs, but there are also the very shallow zones of the laser radiation penetration into the material, and at the same time, there are also the small zones of structural changes. 
For such parameters of laser texturing, very good results of modifying surface layer can be achieved, but only from nano- to microscale.

\section{Conclusions}

As a result of the laboratory tests on the effects of laser remelting of $100 \mathrm{CrMnSi} 6-4$ bearing steel, the following conclusions were drawn:

With the use of an innovative method of laser texturing of roller tracks of roller bearings, a very interesting stereometry of the technological surface of the top layer of $100 \mathrm{CrMnSi}-4$ steel was obtained. It had the characteristic micro-reservoirs of a lubricating agent, which can be very important in the tribological processes of friction pair roller - bearing raceway.

With the use of different parameters of ablative laser micromachining (power density, frequency rate, the number of pulses in the same zone, degree of covering the surface of micro-reservoirs), the micro-reservoirs of lubricating agent with the diameter of 30-140 $\mu \mathrm{m}$ and the depth of 0.05-4.5 $\mu \mathrm{m}$ were obtained, which may constitute promising results.

Pulsed laser hardening without remelting of the top layer of 100CrMnSi6-4 steel, pre-hardened by volume and low tempered $(610 \div 660 \mathrm{HV} 0.05)$, resulted in the fragmentation of the microstructure and an increase in hardness of up to about $800 \div 100$ HV0.05, whereas laser hardening with the effect of the local micro remelting, caused an increase in hardness in relation to the core of the material up to $1100 \mathrm{HV} 0.05$.

The existence of martensitic microstructures was found in the base material after volume hardening and low tempering. As a result of the secondary laser hardening of the steel surface layer, the fragmentation of martensite packets occured, which resulted in the increase of hardness. The highly dispersive martensitic microstructures in the melted and hardened zone near the surface were found in the melted and hardened areas.

The martensitic-bainitic and bainitic microstructure was found in the transition zone. Those microstructures were the result of the ultrafast phase transformations occurring during the crystallisation of Fe-C-Cr-Mn-Si alloy from the liquid phase formed during laser micro remelting.

The obtained results are promising and can significantly affect the improvement of the conditions of friction tribological combination roller-large-size raceway of roller bearing. To confirm the rightness of the thesis of a positive impact of ablative laser texturing, the tribological laboratory tests, mechanical properties tests and fatigue tests should be carried out. This gives great chances of technological applications of the laser texturing ablation process in the production of rolling bearings elements.

There were no micro-cracks in the top surface layer of bearing steel and in cross-section made by the laser melted zone.

\section{Acknowledgement}

The investigation was founded by the National Centre for Research and Development- Project No. PBS1/B5/1/2012/.

\section{REFERENCES}

[1] T. Burakowski, W. Napadłek, J. Marczak, Ablative laser micromachining in areology, Inżynieria Materiałowa 5, 882-889 (2006).

[2] http://www.wama.com.pl/pobierz/lozyskatoczne_calosc.pdf

[3] B. Antoszewski, The surface layers of texture formation undled selected technologies and tribological properties. Kielce University of Technology, Kielce 2010.

[4] http://www.skf.com/skf/productcatalogue/jsp/portal/printerFriendly.jsp?maincatalogue $=1 \&$ lang $=$ pl\&newlink $=5$ _ 15 _020300\&lev el $=5 \&$ ptparent $=1 \_$/

[5] S. Son, H. Lim, A.S. Kumar, M. Rahman, Influences of pulsed power condition on the machining properties in micro EDM, Journal of Materials Processing Technology 190, 73-76 (2007).

[6] W. Napadłek, Investigation of the effect of laser hardening on selected properties of steel $40 \mathrm{H}$. Military University of Technology Warsaw 2002.

[7] S. Schreck, K.-H. Zum Gahr, Laser-assisted structuring of ceramic and steel surfaces for improving tribological properties. Germany Forschungszentrum Karlsruhe $\mathrm{GmbH}$, Institute for Materials Research 2005.

[8] G. Ryk, Y. Klingerman, I. Etsion, Experimental investigation of laser surface texturing for reciprocating automotive components, Tribology Transactions 45, 444-449 (2002).

[9] W. Napadłek, An example of technology applications ablative laser micromachining in tribology, Tribologia 6, 81-89 (2009).

[10] H.J. Hegge, J.Th.M. De Hosson, Microstructure of laser treated Al alloys, Acta metal. Mater. 38 (12), 2471-2477 (1990).

[11] M.H. Cho, S.J. Kim, R.H. Basch, J.W. Fash, H. Jang, Tribological study of gray cast iron with automotive brake linings: The effect of rotor microstructure, Tribology International 36, 537-545 (2003).

[12] W. Napadłek, Laser ablation surface layer texturing of selected Fe-C alloy. Journal of Achievements of Materials and Manufacturing Engineering 55 (2), 748-751 (2012).

[13] M.A. Maleque, S. Dyuti, M.M. Rahmann (member IAENG), Material selection method in design of Automotive brake disc, Proceedings Of The World Congress Of Engineering, London 2010.

[14] P. Kosbe, C. More, Performance of a disc brake friction material, Frontiers in Automobile and Techanical Engineering (FAM) 25-27, 383-386 (2010).

[15] Ch. Zhi-kai, L. Shu-Chao, S. Xi-bin, Z. Haifeng, Y. Wan-Shi, Z. Hong, Effects of bionic units on the fatigue wear of ray cast iron surface with different shapes and distributions, Optics\&Laser Technology 66, 166-174 (2015). 